\title{
In memory of Professor He Yang
}

\author{
Yi Qin* \\ Editor-in-Chief of the Journal of Manufacturing Review
}

The University of Strathclyde, UK

Received 14 October 2016

\begin{abstract}
We were all saddened by the loss of Professor He Yang, Associate Editor of Manufacturing Review, who passed away in 27th September 2016. His loss is a huge loss not only to the Chinese research community and his industrial collaborators but also to the scholars and researchers world-wide in engineering plasticity and technologies and journal of Manufacturing Review, manufacturing research in general.
\end{abstract}

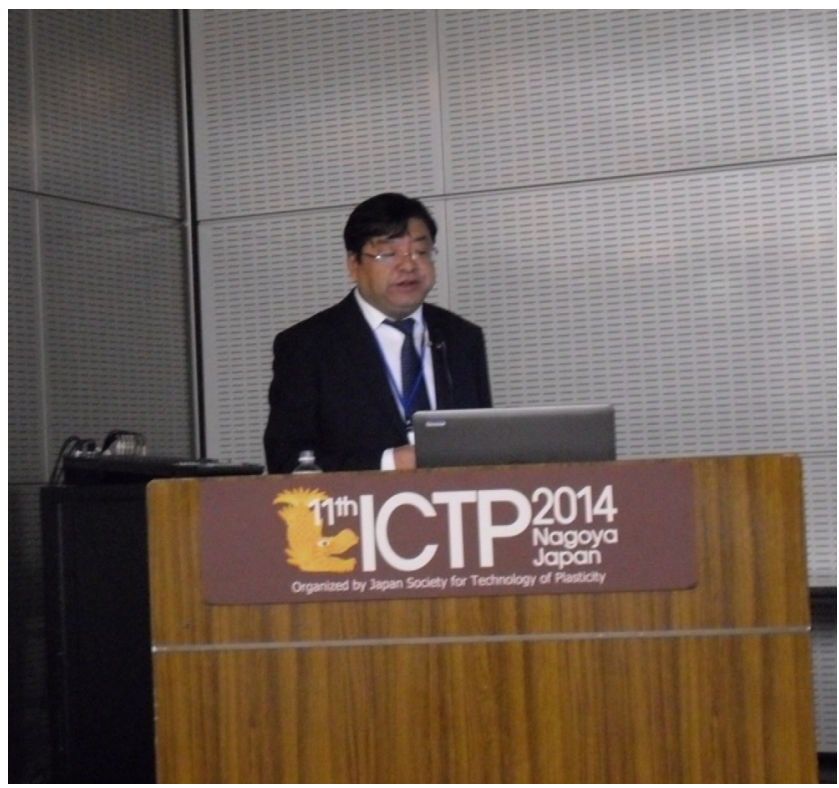

Figure 1. Professor He Yang gave the keynote speech at the ICTP2014 in Japan.

We were all saddened by the loss of Professor He Yang, Associate Editor of Manufacturing Review, who passed away in 27th September 2016, due to a sudden illness. Prof. Yang was very supportive to the journal and made significant contributions to the setup of this journal, since we all saw need and significance to have such a journal in the field of manufacturing research.

As a world leader himself in the research and industrial applications of technologies of plasticity, Prof. Yang's contributions to knowledge in engineering plasticity and technologies

\footnotetext{
*e-mail: qin.yi@strath.ac.uk
}

are world-wide well-known, especially in the field of precision metal forming. Notably, he proposed theory and technological realisation of active use and control of non-uniform deformations to achieve high-performance and lightweight forming integration for difficult-to-deform materials and complex structures/components, for which he and his team in Northwestern Polytechnical University (NPU) of China, made remarkable progress in research and applications, and became a world leader in this field of research. As the President of China Society for Technology of Plasticity, he guided the Chinese community of research in technologies of plasticity to achieve wonderful progress and reputation in engineering plasticity and technologies over the last 5 years. In fact, due to his and his colleagues' effort, China's engagement with world-wide players in research in plasticity engineering has remarkably increased during the last 10 years. All the scholars/researchers worldwide in engineering plasticity and technology research are benefiting from the significant contributions from the scholars/researchers from China, and we all enjoy and are grateful for their work published in a variety of international journals, including ones published in Manufacturing Review. According to my own investigation, over $50 \%$ of the scientific/technical papers published in the journals on precision forming/forging topics during the last 10 years have been contributed from China. Professor Yang himself was also actively involved with ICTP series conferences and various journals' editorial boards, including giving a keynote speech at the ICTP2014 in Japan.

The first time when I met Prof. Yang was the Annual Conference of China Society for Technology of Plasticity, being held in Chongqing in 2011, during which Prof. Yang and me had good introduction to each other and then lengthened exchanges on how Western Scholars see the contributions from China in the research in engineering plasticity and technologies. I had feeling that he was very keen to see more Chinese scholars to play more significant roles in the world stage. Then, we fortunately took a same flight from Chongqing 


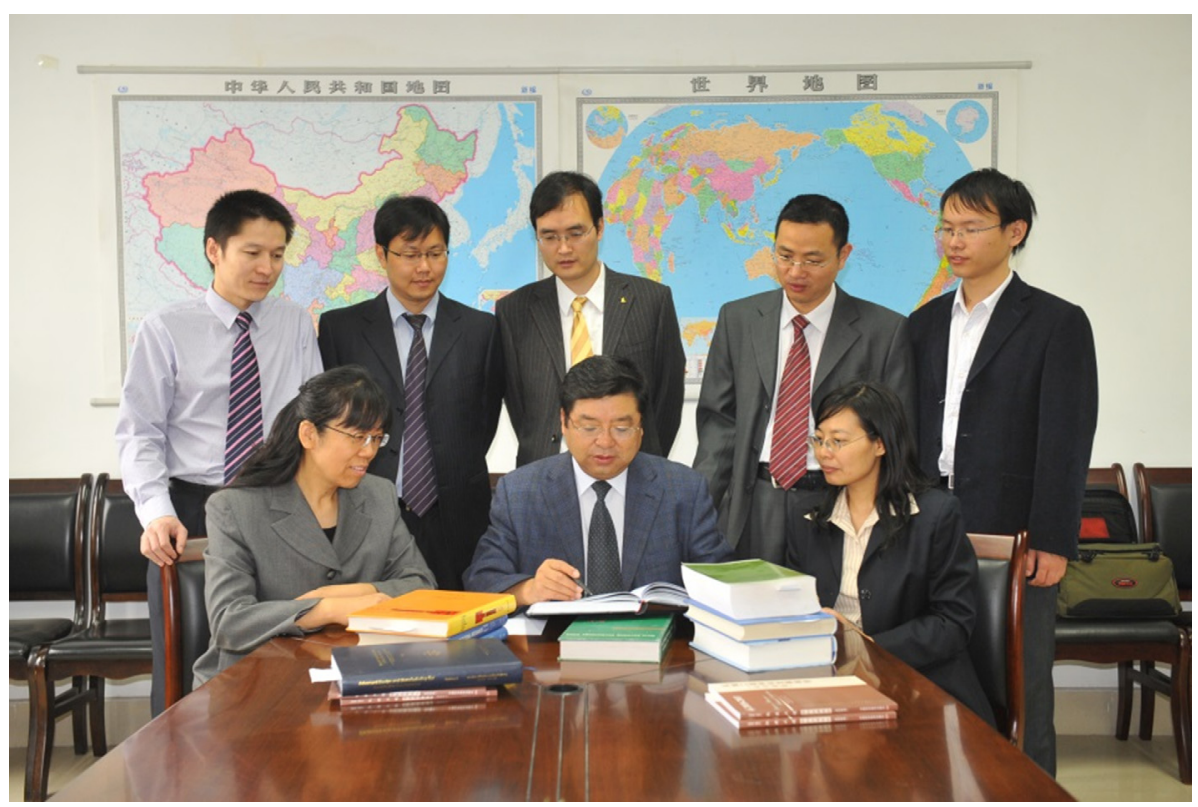

Figure 2. Professor He Yang and his group's core members of academic staff at NPU.

to Harbin to attend an Global Manufacturing Professor Forum. During the trip, we had more exchanges of our thoughts and saw more clearly our views on how metal forming research directions should go. Before the 10th International Conference on Technology of Plasticity (ICTP) (2011), held in Aachen, Germany, I acquired his help for inviting 15 Professors from the China Society of Technology of Plasticity to attend a dinner with a view to exchanging ideas and to discussing potential collaborations with China. The dinner went very well, from which I also felt his respected authority and strong friendship with his colleagues. When I talked to Prof. Yang on the idea of setting up the journal of Manufacturing Review with EDP Sciences in France, he was very keen to see the development of the idea into a reality. We had also several discussions after the journal started in 2013, especially, through my visit to Northwestern Polytechnical University in 2014, during which I received pleasant hospitality from Prof. Yang and his team. We discussed not only about the journal but also potential collaborations in research. I shall never forget my exceptional departure from my hotel in Xi'an when Prof. Yang and his whole team of professors to come to the hotel to send me away - what farewell was! When I arrived at the Xi'an airport, I was arranged to have a lunch in one of the restaurants at the airport with his $\mathrm{PhD}$ student who accompanied me to the airport, since he was "ordered" by Prof. Yang to do so! All of these made me feel great kindness from Prof. Yang and his team. I wished that one day I could do the same for Prof. Yang, but unfortunately he didn't manage to come to Glasgow to attend the 4th International Conference on New Forming Technology, held in August 2015. However, he did send a big team to attend, with his best wishes to the conference.

More I knew Prof. He Yang, I have more respect to his achievements both as a person and as a world leader in the research and engineering applications in technologies of plasticity. His loss is a huge loss not only to the Chinese research community and his industrial collaborators but also to the scholars and researchers world-wide in engineering plasticity and technologies and journal of Manufacturing Review, manufacturing research in general. 